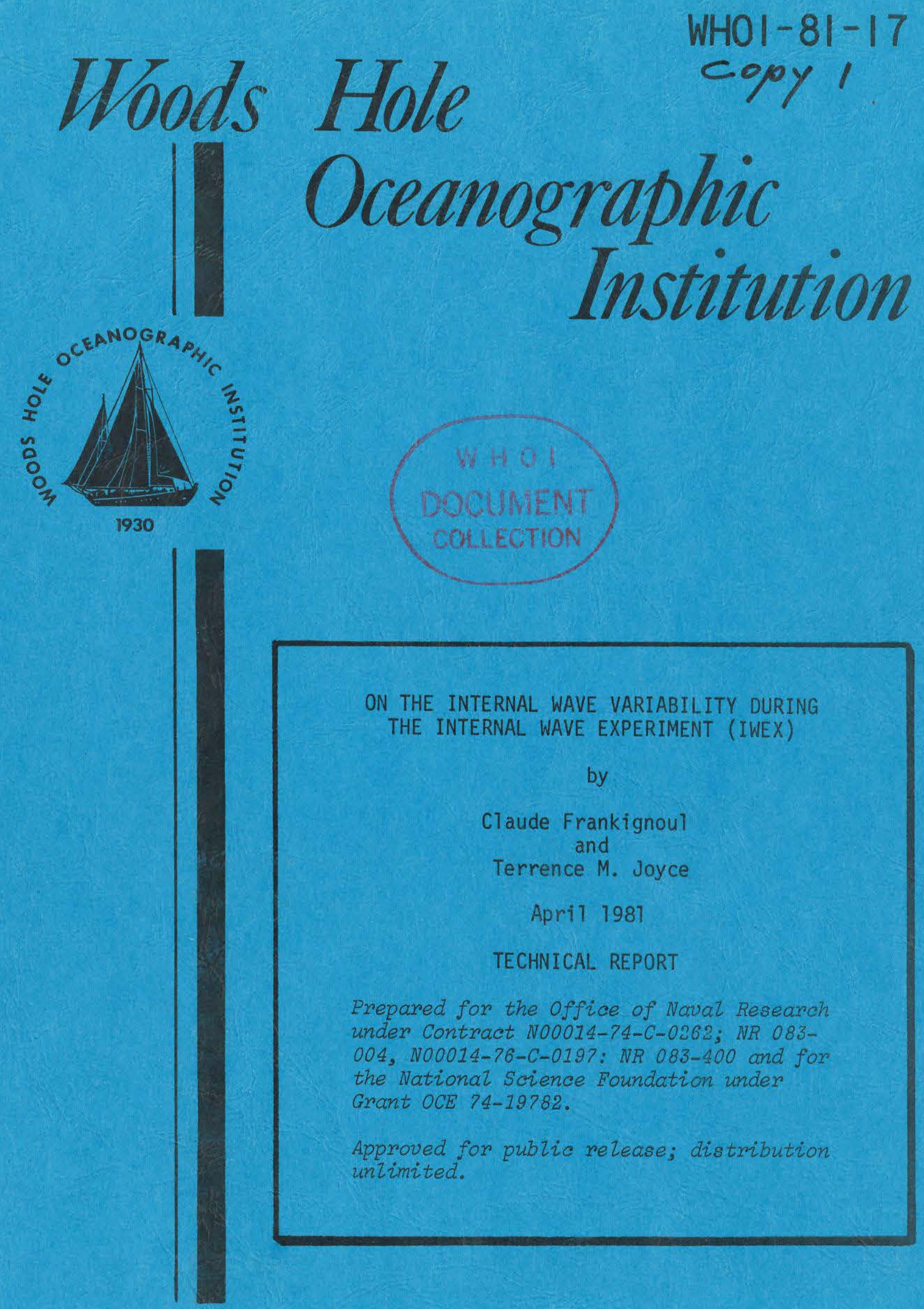

WOODS HOLE, MASSACHUSETTS 02543 


$$
\text { WHOI -81-17 }
$$

ON THE INTERNAL WAVE VARIABILITY DURING THE INTERNAL WAVE EXPERIMENT (IWEX)

by

\author{
Claude Frankignoul \\ and \\ Terrence M. Joyce
}

WOODS HOLE OCEANOGRAPHIC INSTITUTION

Woods Hole, Massachusetts 02543

Apri1 1981

TECHNICAL REPORT

Prepared for the Office of Naval Research under Contracts IN00014-74-C-0262; NR 083-004, N00014-76-C-0197: NR 083400 and for the National Science Foundation under Grant OCE 74-19782.

Reproduction in whole or in part is permitted for any purpose of the United States Govermment. In citing this report in a bibliography, the reference given should be to: Journal of Geophysical Research 84 (C2): 769-776. (February 1979).

Approved for public release; distribution unlimited.

Approved for Distribution: Valentine Worthington, Chairman Department of Physical Oceanography 


\title{
On the Internal Wave Variability During the Internal Wave Experiment (IWEX)
}

\author{
Claude Frankignoul
}

Department of Meteorology, Massachusetts Institute of Teihnology. Cambridge, Massachusetts 02139

TERRENCE M. JoYCE

Woods Hole Oceanographic Institution, Woods Hole, Massachusetts 03143

\begin{abstract}
The relation between internal wave variability and larger and smaller scales of motion is investigated, using the IWEX data set. To investigate the role of internal waves in the vertical diffusion of large scale momentum, the time variability of the vertical flux of horizontal internal wave momentum (estimated from temperature and current data) is compared to that of the mean vertical shear. It is found that internal waves cannot cause a vertical viscosity as large as proposed by Müller (1976), but that the data are too noisy to detect a possible wave-induced viscosity in absolute value of the order of $10^{-2} \mathrm{~m}^{2} \mathrm{~s}^{-1}$ or less. Similarities in the time behavior of the total internal wave energy and that of the square mean vertical shear suggest that some kind of dynamical coupling exists between internal waves and larger scale flows. There is some evidence that the level of temperature finestructure activity also varies in a related way. An analysis of CTD station data taken during Mode demonstrates the mappability of the finestructure activity, and again suggests a relation with the geostrophic eddy flow.
\end{abstract}

\section{INTRODUCTION}

Bretherton [1966] has shown that a train of linear internal gravity waves can only exchange momentum with larger scale flows at critical levels. However, critical levels are unlikely to be frequently found in the ocean, hence it was believed that internal waves do not contribute significantly to the diffusion of mean flow momentum. However, Müller [1976] has recently suggested that the interaction between internal waves and quasi-geostrophic motions lead to an important diffusion of mean flow momentum (but no vertical diffusion of mass), provided relaxation processes within the internal wave field are taken into account. For strong relaxation processes, the interaction should be essentially local in space and time and the diffusion of momentum can be represented by diffusion coefficients. On the basis of calculations by Olbers [1976], Muller introduced a relaxation time (for simplicity, independent of wavenumber) of the order of 5 days, and predicted a large wave-induced vertical viscosity $\nu_{v}=0.4 \mathrm{~m}^{2} \mathrm{~s}^{-1}$ and a moderate horizontal viscosity $\nu_{h}=7 \mathrm{~m}^{2} \mathrm{~s}^{-1}$. Müller and Olbers [1975] also proposed a rather consistent zero-order energy balance for the deep sea internal wave field: energy input from the mean flow, redistribution of this energy by resonant wavewave interactions and dissipation at high vertical wavenumber and low frequencies, presumably by wave breaking, so that internal waves would be contributing significantly to the vertical diffusivity of mass.

The empirical testing of these ideas has been inconclusive. Frankignoul [1976] found evidence in a portion of the MODE currentmeter data that the internal wave continuum in the vicinity of the main thermocline contributes positively to the horizontal diffusion of mean flow momentum and has a relaxation time of about 1-4 days. This is consistent with Müller's theory, but attempts to observe the predicted vertical viscosity have failed. Ruddick and Joyce [1978] found in Polymode currentmeter data that the vertical flux of horizontal wave momentum was one order of magniture smaller than Müller's prediction, and uncorrelated with local shears in regions of low eddy activity, where the theory should be applicable. The

Copyright (c) 1979 by the American Geophysical Union.

Paper number $8 \mathrm{C} 0839$.

0148-0227/79/008C-0839\$01.00
IWEX data analyzed in this paper show a similar lack of correlation. This suggests that the internal wave vertical viscosity (if any) is at least 1 order of magnitude smaller than predicted by Müller [1976], consistent with McComas and Bretherton [1977] and McComas [1977], who showed that the nonlinear processes controlling the vertical symmetry of the internal wave field have much shorter characteristic time scales than the nonlinear interactions in a symmetric spectrum like the one considered by Olbers [1976], thereby reducing significantly Müller's viscosity.

Field data are nevertheless suggestive of an interaction between internal waves and geostrophic eddies. Frankignoul [1976] observed during Mode that the total internal wave energy (dominated by near-inertial oscillations) was behaving like the square mean vertical shear, consistent with a quasilocal interaction and a somewhat smaller vertical viscosity than in Müller [1976]. The observed correlation did not have a very large statistical significance, but Ruddick and Joyce [1978] report similar results at Polymode moorings with strong currents. They also observed that the fluctuations in shear lead somewhat those of internal wave energy and that the square mean velocity was equally well correlated with the other variables. At other moorings, with lower eddy activity the correlations were too small to be significant. During IWEX, some similarity between internal wave energy and square mean shear is also observed, as reported below. A novel feature of this study is that we could also monitor the changes in the finestructure activity. These changes show interesting correspondences with the fluctuations in the eddy and internal wave fields.

In the present paper, we investigate the variability of the internal wave field during IWEX, with emphasis on the empirical testing of the dynamical role of internal waves. Preliminary results of IWEX have been discussed by Briscoe [1975]. The specification of a kinematic model of the mean internal wave field is reported by Müller et al. [1978]. Gaussianity is discussed by Briscoe [1977], temperature finestructure by Joyce and Desaubies [1977], turning point effects by Desaubies [1975] and the low frequency current and temperature fields by Bryden [1976]. 
TABLE 1. Records of Velocity $\mathbf{u}$ and Temperature $T$ Used in This Study

\begin{tabular}{|c|c|c|c|c|c|}
\hline \multirow[b]{2}{*}{ Level } & \multicolumn{3}{|c|}{ Leg } & \multirow[b]{2}{*}{ Depth, m } & \multirow[b]{2}{*}{$N$, cph } \\
\hline & A & B & $\mathrm{C}$ & & \\
\hline 1 & $u, T$ & & $T$ & 604 & 2.5 \\
\hline 2 & $T$ & $T$ & $T$ & 606 & 2.5 \\
\hline 4 & u. $T$ & $u, T$ & & 611 & 2.5 \\
\hline 5 & u. $T$ & $u, T$ & $u, T$ & 639 & 2.6 \\
\hline 6 & $T$ & $T$ & $u, T$ & 731 & 2.7 \\
\hline 8 & $T$ & & & 1014 & 2.1 \\
\hline 10 & $T$ & $u, T$ & $u, T$ & 1023 & 2.1 \\
\hline 14 & $u, T$ & $T$ & $T$ & 2050 & 0.7 \\
\hline
\end{tabular}

$N$ is the buoyancy frequency estimated from CTD profiles at the beginning and end of the experiment.

In section 2, the short but highly accurate IWEX data are described, and the method of analysis is presented. The accuracy of the internal wave Reynolds stress estimates is discussed in section 3, and their time variability compared to variations in the mean vertical shear in section 4 . The time variability of the internal wave energy is described in section 5, and compared to fluctuations in the square mean vertical shear. In section 6 , we discuss the temporal variability of the temperature finestructure intensity as inferred from moored measurements of vertical temperature differences. This is shown to be similar to spatial variability of temperature finestructure, which was mapped for a single 12 day period during the Mode experiment.

\section{Data DESCRIPTION AND ANALYSIS}

The basic data set collected during IWEX has been described by Briscoe [1975] and Tarbell et al. [1976], and only a short summary is given here. A trimoored array of sensors was placed in the Sargasso Sea at $27^{\circ} 44^{\prime} \mathrm{N}, 69^{\circ} 51^{\prime} \mathrm{W}$ for 42 days. The trimooring was nearly a perfect tetrahedron, approximately $6 \mathrm{~km}$ on a side, and the apex was at the top of the thermocline at $600 \mathrm{~m}$ depth. The mooring was very stable, $\pm 0.2 \mathrm{~m}$ vertical motion at the apex float, $\pm 1 \mathrm{~m}$ at $1000 \mathrm{~m}$ depth. The main array was located between 604 and $1023 \mathrm{~m}$ depth and the instruments spaced nominally in a logarithmic fashion: 17 modified vector averaging current meters (VACM) measured the east $\left(u_{1}\right)$ and north $\left(u_{2}\right)$ current components, the temperature $T$ and the temperature difference $\Delta T$ at $1.74 \mathrm{~m}$ vertical separation, with $225 \mathrm{~s}$ sampling intervals. In addition,

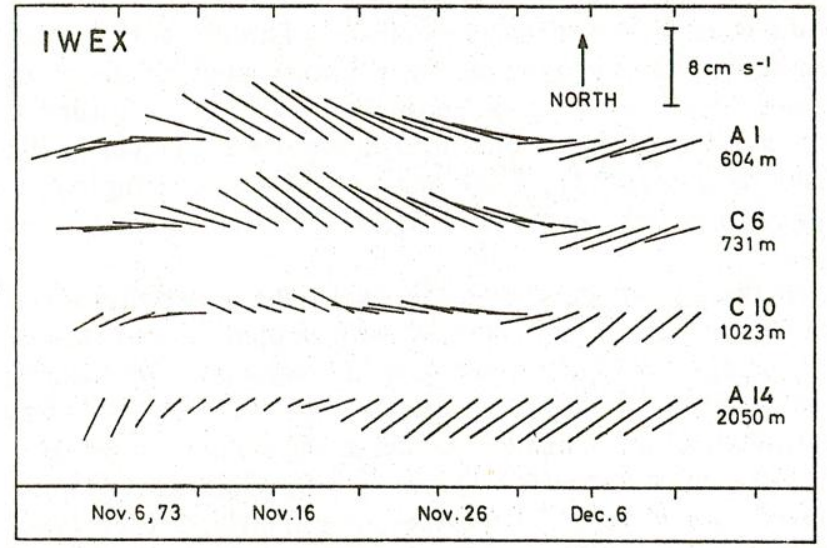

Fig. 1. Time series of the low-frequency current vectors at four different depths. three Geodyne 850 current meters measured $u_{1}, u_{2}$, and $T$ at $2050 \mathrm{~m}$ depth, with $900 \mathrm{~s}$ sampling intervals.

The instruments considered in this study (Table 1) gave high quality data for the whole duration of the experiment, except at $2050 \mathrm{~m}$, where the high frequency currents are not reliable during the first 20 days because the current meter rotors were often below the threshold point. All records were divided into 25 overlapping pieces of $75 \mathrm{hr}$ (the local inertial period is 25.8 $\mathrm{hr}$ and the M2 tidal period $12.4 \mathrm{hr}$ ). The vertical displacement is estimated by

$$
\zeta(t)=-T(t)\left(\frac{\langle\Delta T\rangle}{\Delta x_{3}}\right)^{-1}
$$

where $\langle\Delta T\rangle$ is the mean temperature difference in each piece. The vertical velocity $u_{3}$ is constructed by time differencing of (1). Each piece was Fourier analyzed after application of a cosine bell window, providing estimates of the co-spectra $C_{i j}(\omega ; t)$ and quad-spectra $Q_{i j}(\omega ; t)$ between time series $i$ and $j$ at $37.5 \mathrm{hr}$ intervals. These were subsequently averaged into two broad frequency bands. The 'total band' covers practically the whole internal wave frequency range [0.04-2.4 cph], whereas the 'continuum band' is limited to the internal wave continuum [0.1-2.4 cph]. Since the piece length (75 hr) corresponds to the spectral gap between internal wave and quasigeostrophic eddy frequencies, we are considering the variations of the internal wave statistical properties on the eddy time scale. In the following, high frequency fluctuations are denoted by a prime, low frequency ones by angle brackets.

Corresponding time series of the mean currents $\langle\mathbf{u}\rangle(t)$ were obtained by applying a Gaussian filter of $75 \mathrm{hr}$ width to the 25 pieces (Figure 1). Time series of the mean vertical shear $\partial\langle\mathbf{u}\rangle /$ $\partial x_{3}$ are constructed by differencing these data above and below the level considered. For small vertical separation between the instruments (up to a few hundred meters), the shear cannot be properly estimated since the changes in horizontal current

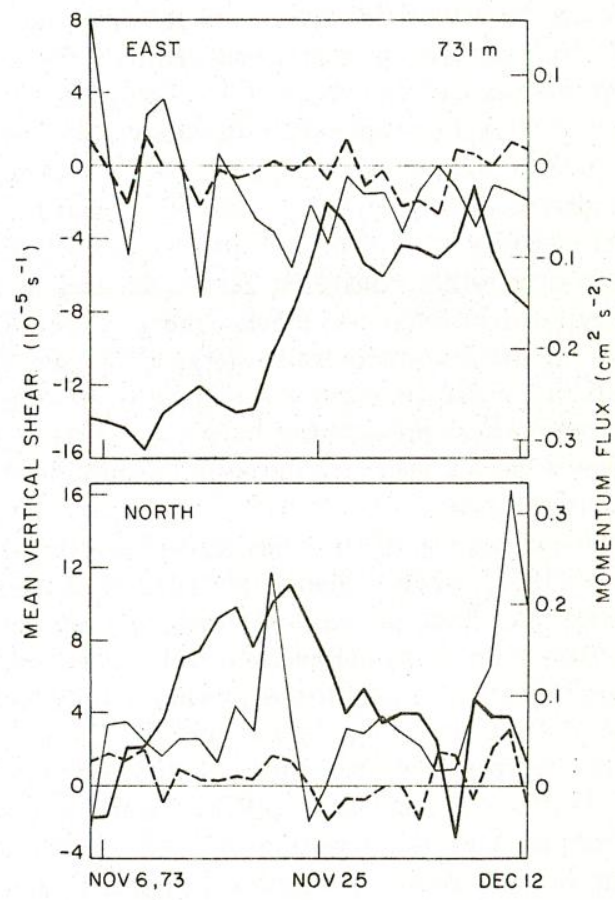

Fig. 2. Time behavior of the mean vertical shear (thick line) and of the vertical flux of horizontal momentum in the continuum band (dashed line) and in the total band (thin line) at $731 \mathrm{~m}$. 


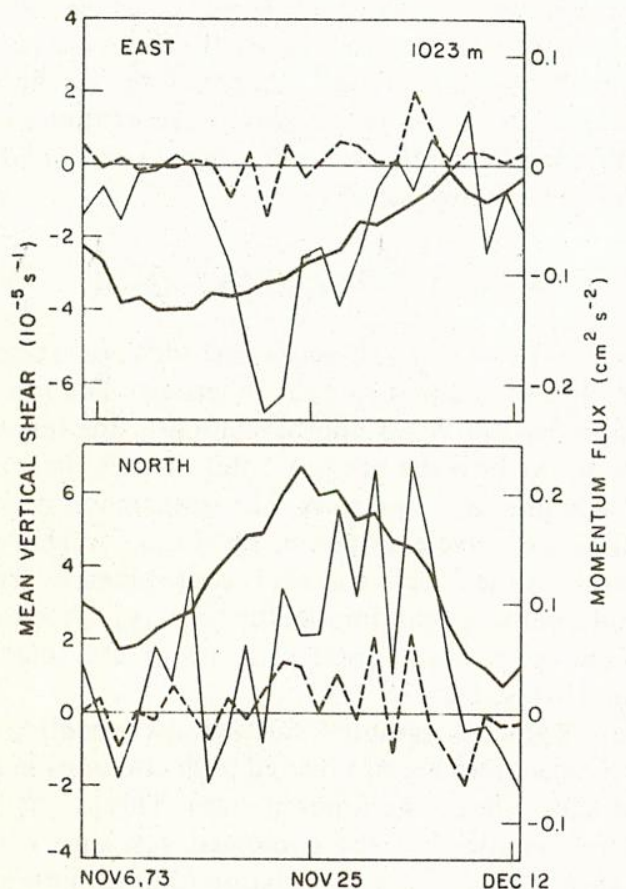

Fig. 3. Time behavior of the mean vertical shear (thick line) and of the vertical flux of horizontal momentum in the continuum band (dashed line) and in the total band (thin line) at $1023 \mathrm{~m}$.

direction are of the order of the instrumental uncertainty in each direction [Bryden, 1976]. Hence, the shear has only been estimated at two levels. At $731 \mathrm{~m}$, the shear is constructed by differencing between the averaged velocity at 604 and $639 \mathrm{~m}$, and the averaged velocity at 731 and $1023 \mathrm{~m}$ (Figure 2). Because we lack current measurement above $600 \mathrm{~m}$, these shear estimates appear to be noisy, but unbiased. At $1023 \mathrm{~m}$, the shear is constructed from the currents at 731 and $2050 \mathrm{~m}$ (Figure 3). These estimates seem less noisy than at $731 \mathrm{~m}$, but biased. Indeed, comparison with typical profiles $\langle u\rangle\left(x_{3}\right)$ in the same region, as reported by Sanford [1975], suggest that the shear at $1023 \mathrm{~m}$ is systematically underestimated by a factor of 2 at least.

\section{Estimation of the Vertical Flux of Horizontal Momentum}

The vertical velocity $u_{3}$ was not measured directly but constructed from the temperature data through relation (1). This relation is a simplified version of the heat balance equation and the neglected terms can cause significant errors. The internal wave contribution to $\left\langle u_{\alpha}{ }^{\prime} u_{3}{ }^{\prime}\right\rangle$ is obtained by considering cospectra $C_{\alpha 3}$ instead of covariances, and by limiting the former to internal wave frequencies. This filters out low and high frequency noise but does not eliminate the finestructure contamination of temperature and velocity. Here we discuss the different sources of noise affecting $C_{\alpha 3}(\omega ; t)$ during IWEX. A more thorough error analysis is given by Ruddick [1977]. Note that the Polymode data are more contaminated since mooring motions were large and had to be corrected for, and the mean temperature gradient was not measured at each instrument.

Stress estimates. The temperature equation can be written

$\frac{\partial T^{\prime}}{\partial t}+\left\langle u_{\beta}\right\rangle \frac{\partial T^{\prime}}{\partial x_{\beta}}+u_{\beta}^{\prime}\left\langle\frac{\partial T}{\partial x_{\beta}}\right\rangle+u_{i}^{\prime} \frac{\partial T^{\prime}}{\partial x_{i}}-\left\langle u_{i}^{\prime} \frac{\partial T^{\prime}}{\partial x_{i}}\right\rangle$

$$
+u_{3}^{\prime} \frac{\partial\langle T\rangle}{\partial x_{3}}=K \frac{\partial}{\partial x_{i}} \frac{\partial}{\partial x_{i}} T^{\prime}
$$

where we have assumed zero mean vertical velocity and constant thermal diffusion coefficient $K$, with $\alpha, \beta=1,2$ and $i=1$, 2,3 . Multiplying by $u_{\alpha}{ }^{\prime}$ and averaging yields

$$
\begin{aligned}
\left\langle u_{\alpha}{ }^{\prime} \frac{\partial T^{\prime}}{\partial t}\right\rangle & +\left\langle u_{\beta}\right\rangle\left\langle u_{\alpha}{ }^{\prime} \partial T^{\prime} / \partial x_{\beta}\right\rangle \\
& +\left\langle u_{\alpha}{ }^{\prime} u_{\beta}{ }^{\prime}\right\rangle \frac{\partial\langle T\rangle}{\partial x_{\beta}}+\left\langle u_{\alpha}{ }^{\prime} u_{i}^{\prime} \partial T^{\prime} / \partial x_{i}\right\rangle+\left\langle u_{\alpha}{ }^{\prime} u_{3}{ }^{\prime}\right\rangle \frac{\partial\langle T\rangle}{\partial x_{3}} \\
& =K\left\langle u_{\alpha}{ }^{\prime} \partial / \partial x_{l} \partial / \partial x_{i} T^{\prime}\right\rangle
\end{aligned}
$$

Using relation (1) is equivalent to keeping only the first and fifth terms.

The second term is induced by Doppler shift and can be readily compared to the first term by

$$
\frac{\left\langle u_{\beta}\right\rangle\left\langle u_{\alpha}{ }^{\prime}\left(\partial T^{\prime} / \partial x_{\beta}\right)\right\rangle}{\left\langle u_{\alpha}{ }^{\prime}\left(\partial T^{\prime} / \partial t\right)\right\rangle}=\frac{\left\langle u_{\beta}\right\rangle}{\left\langle C_{\beta}\right\rangle} \ll 1
$$

where $C$ is the internal wave phase speed, much larger than the relatively small current velocities observed during IWEX (cf. Figure 1). Using a spectral model of the internal wave field, Ruddick [1977] estimates the ratio (4) to be no more than $5 \%$. This small noise is proportional to $\langle\mathbf{u}\rangle$.

The third term represents the horizontal advection of mean temperature by internal waves and the ratio of the third term to the fifth term can be estimated directly from the data. Using relation (1), we write

$$
\left|\frac{\left\langle u_{\alpha}{ }^{\prime} u_{\beta}{ }^{\prime}\right\rangle\left(\partial\langle T\rangle / \partial x_{\beta}\right)}{\left\langle u_{c}{ }^{\prime} u_{3}{ }^{\prime}\right\rangle\left(\partial\langle T\rangle / \partial x_{3}\right)}\right|=\left|\frac{\left\langle u_{c}{ }^{\prime} u_{\beta}{ }^{\prime}\right\rangle f}{\left\langle u_{c}{ }^{\prime} u_{3}{ }^{\prime}\right\rangle N^{2}} \frac{\partial\left\langle u_{\gamma}\right\rangle}{\partial x_{3}}\right|
$$

where $f$ is the Coriolis parameter, $N$ the Brunt-Väisälä frequency, and $\gamma=1,2$ for $\beta=2,1$, respectively. Here we have used the thermal wind relation to express horizontal density gradients as a function of vertical shears and assumed that the vertical temperature and density gradients are proportional. This seems permissible, since a very tight $T / S$ relationship holds in the Sargasso Sea. Low frequency fluctuations in the mean vertical temperature gradient $\Delta\langle T\rangle / \Delta x_{3}$ at 731 and 1023 $\mathrm{m}$ were at most $15 \%$ of the means, hence the use of a constant value for $N$ in (5) introduces little error. The ratio (5) can now be estimated from the calculated co-spectra $C_{\alpha \beta}$ and $C_{\alpha 3}$. To reduce the statistical uncertainties, we have used time-space averages (after WKB scaling) for the whole IWEX array down to level 10. Taking $\partial\left\langle u_{1}\right\rangle / \partial x_{3}=3 \times 10^{-5} \mathrm{~s}^{-1}$ and $\partial\left\langle u_{2}\right\rangle / \partial x_{3}=$ $10^{-4} \mathrm{~s}^{-1}$ as representative values of the shear at 731 and 1024 $\mathrm{m}$, we find that the ratio (5) is about $15 \%$ near $\omega=f, 10 \%$ at $f$ $<\omega<0.1 \mathrm{cph}$ and generally less than $5 \%$ at $\omega>0.1 \mathrm{cph}$. The dominant contribution in the third term in (1) induces errors in $C_{\alpha 3}$ proportional to the shear at right angle.

Scale analysis for weakly nonlinear internal waves suggests that the fourth term in (1) is unimportant. The diffusive term (sixth term in (1)) can be compared to the first term. Using the wave dispersion relation, one has

$$
\frac{K\left\langle u_{\alpha}{ }^{\prime}\left(\partial / \partial x_{i}\right)\left(\partial / \partial x_{i}\right) T^{\prime}\right\rangle}{\left\langle u_{\alpha}{ }^{\prime}\left(\partial T^{\prime} / \partial t\right)\right\rangle} \approx \frac{N^{2} \alpha^{2} k}{\omega\left(\omega^{2}-f^{2}\right)}
$$

where $\alpha$ denotes the horizontal wavenumber. If we choose for $K$ the molecular diffusivity, the sixth term is always negligible (except at $\omega \approx f$ ). For larger 'turbulent' diffusivities, the sixth term may be important at low frequencies. 
The largest source of error in the internal wave stress estimates may be the temperature and current finestructure that contaminate the recorded signal, especially at high frequencies [Joyce and Desaubies, 1977]. Müller et al. [1978] have shown empirically that the relative temperature finestructure contamination increases with increasing frequencies, accounting for about $10 \%$ of the measured energy at high frequencies. The velocity finestructure contamination, added to the currentmeter noise, is more important. Although their combined effects are small near $\omega=\int$ they account for about $30 \%$ of the measured energy at $\omega=0.1 \mathrm{cph}$ and become comparable to the wave energy at $\omega \geq 1 \mathrm{cph}$. Lacking any combined velocity/ temperature finestructure model, we cannot estimate the resulting contamination of $C_{\alpha 3}$, which depends upon the correlation between velocity and temperature fine structure. Errors ranging between $5 \%$ near $f$ up to $50 \%$ at high frequencies do not seem unreasonable.

In summary, the estimates of the vertical flux of internal wave horizontal momentum are rather noisy, perhaps with $20 \%$ error at medium frequencies and more at very low and very high frequencies.

Statistical uncertainties. The statistical uncertainties in the computed cross-spectra can be evaluated in each piece from their standard deviation $\sigma_{\alpha 3}$ about the true value given by [Jenkins and Watts, 1969]

$$
\sigma_{\alpha 3}=\left(\frac{\left\langle u_{\alpha}{ }^{2}\right\rangle\left\langle u_{3}{ }^{2}\right\rangle}{\nu_{e}}\right)^{1 / 2}
$$

Here $\left\langle u_{i}{ }^{2}\right\rangle$ is the variance of the $i$ component of the velocity in the continuum or total band, and $\nu_{e}$ the effective number of degrees of freedom calculated from Nuttal [1971] and Perrson [1974], and corrected for the redness of the cross-spectra (J. Willebrand, private communication, 1976). We have assumed a $\omega^{-1}$ behavior for the stress, consistent with Garrett and Munk [1975], which yields $\nu_{e}=39$ and 59 for the total and continuum band, respectively.

Time series of the stress estimates at 731 and $1023 \mathrm{~m}$ are displayed in Figures 2 and 3. The error bars have not been represented, but none of the estimates is statistically different from zero at the $95 \%$ level of significance. However, the stress in the total band undergoes large fluctuations and periods can be found where the stress estimates, averaged over several pieces to increase $\nu_{e}$, are significantly non-zero. On the other hand, the stress in the continuum band looks more like white noise. The above behavior is consistent with Müller et al. [1978], who found from the whole time averaged IWEX data that the internal wave field was vertically symmetric except at inertial and tidal frequencies. Similarly, Sanford [1975] and Leaman [1976] have observed a downward propagation of near-inertial waves in the same oceanic region. Note that the stress in the total band is largest when the total internal wave energy is largest (Figure 5).

\section{ON THE INTERNAL WAVE-INDUCED VERTICAL VISCOSITY}

If the viscosity concept is applicable to parameterize the effects of internal waves on the mean flow, fluctuations in the wave momentum flux should be related to fluctuations in the mean vertical shear by

$$
\left\langle u_{\alpha}{ }^{\prime} u_{3}{ }^{\prime}\right\rangle=-\nu_{v} \frac{\partial\left\langle u_{\alpha}\right\rangle}{\partial x_{3}}
$$

Müller [1976] pointed out by considering the potential vorticity of the mean flow that the wave horizontal buoyancy flux $\left\langle u_{\beta}{ }^{\prime} b^{\prime}\right\rangle$ was acting on the mean flow as well as the wave vertical flux of horizontal momentum, hence that both fluxes should be taken into account. He found that practically all the 'effective' wave stress was due to the internal wave continuum (at $\omega>$ 2f). This appears clearly in Ruddick and Joyce's [1978] formulation of the effective stress

$$
\left\langle u_{\alpha \gamma}{ }^{\prime} u_{3}^{\prime}\right\rangle^{\mathrm{erf}}=\left\langle u_{\alpha}{ }^{\prime} u_{3}{ }^{\prime}\right\rangle-\frac{f^{2}}{N^{2}} \epsilon_{\alpha \beta \beta 3}\left\langle u_{\beta}^{\prime} b^{\prime}\right\rangle \approx\left\langle u_{\alpha}{ }^{\prime} u_{3}{ }^{\prime}\right\rangle\left(1-\frac{f^{2}}{\omega^{2}}\right)
$$

where $\epsilon_{i j k}=1(-1)$ if $i, j, k$ is an even (odd) cyclic permutation of $1,2,3$, and is equal to zero otherwise. The last relation, derived under the WKB approximation in the horizontal direction, shows how the buoyancy flux cancels the momentum flux at near inertial frequencies. The reduction in stress is small in the internal wave continuum, $3 \%$ if $C_{c r 3}(\omega)$ behaves as $\omega^{-1}$. Since most of the effective stress is contributed by frequencies in the internal wave continuum, the stress $\left\langle u_{\alpha}{ }^{\prime} u_{3}{ }^{\prime}\right\rangle$ in the continuum band provides a good estimate of the total effective internal wave stress.

Figures 2 and 3 suggest that fluctuations in continuum stress (heavy dashed line) are not related to fluctuations in the mean vertical shear (heavy continuous line). This is confirmed by correlation analysis of the combined east and north data, which shows insignificant correlation $(0.2)$ at both levels. Although the slopes of the regression lines are not different from zero in a statistical sense, they are worth reporting, since they define error bars on the eddy viscosity estimates. Assuming no errors in the shear values, one finds

$$
\nu_{v}=(-30 \pm 48) 10^{-4} \mathrm{~m}^{2} \mathrm{~s}^{-1}
$$

at 731 and

$$
\nu_{v}=(-168 \pm 227) 10^{-4} \mathrm{~m}^{2} \mathrm{~s}^{-1}
$$

at $1023 \mathrm{~m}$.

Error bars are $95 \%$ confidence limits, assuming independent samples for the stress estimates, which is substantially correct. The shear is noisy, however, particularly at $731 \mathrm{~m}$. Assuming comparable percentage errors for the shear and stress values increases the estimate (10) by a factor of 6 , and the estimate (11) by a factor of 5 . On the other hand, taking into account the likely underestimation of the vertical shear at $1023 \mathrm{~m}$ (section 2 ) should decrease (11) by a factor of 2 at least. Thus the error bars seem comparable at both levels, and the data are

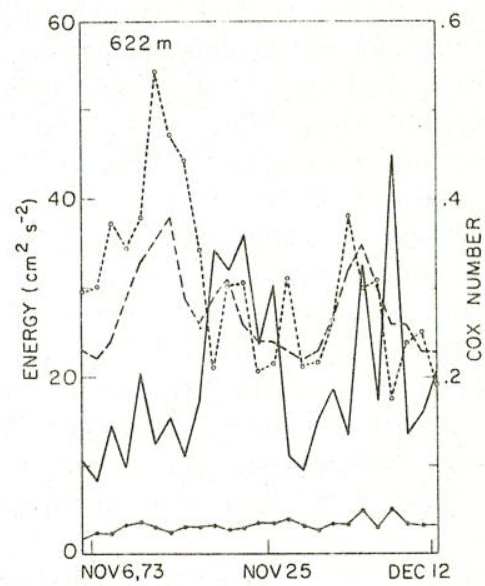

Fig. 4. Time behavior of the total energy in the total band (continuous line) and in the continuum band (lower curve), of the Cox number (dashed line) and of the normalized Cox number (dotted line) near the apex. 


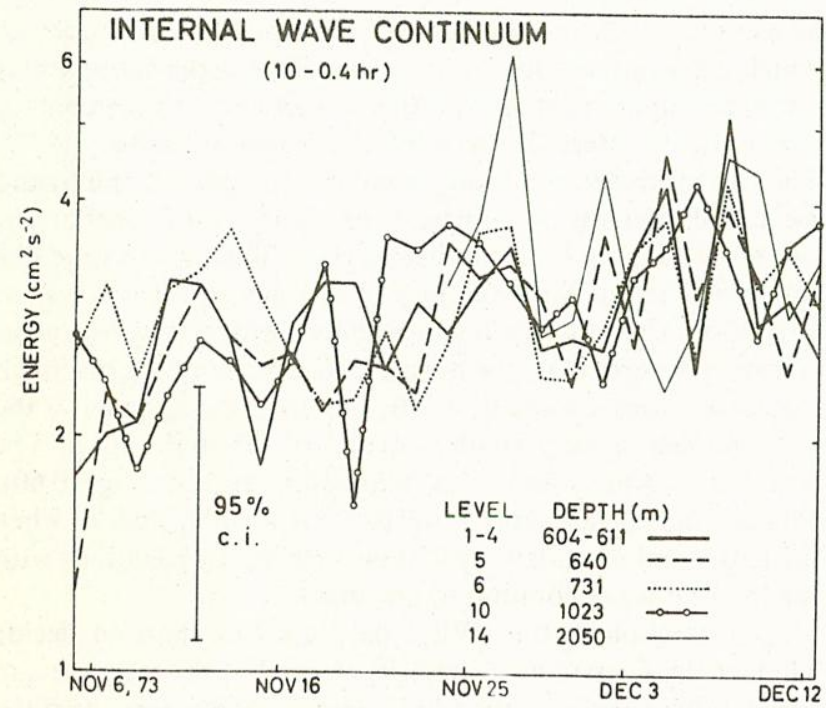

Fig. 5. Time behavior of the total energy in the internal wave continuum at five depths, scaled down $10604 \mathrm{~m}$ in a WKB manner. When several instruments gave good velocity measurements at the indicated level, average spectra have been used. The error bars have been estimated by assuming a $\omega^{-2}$ spectral slope.

too noisy to detect a wave-induced vertical viscosity, if any, of absolute value of the order of $10^{-2} \mathrm{~m}^{2} \mathrm{~s}^{-1}$. Nonetheless, the IWEX data do not support the large value of the vertical viscosity $\left(4 \times 10^{-1} \mathrm{~m}^{2} \mathrm{~s}^{-1}\right)$ proposed by Müller [1976].

Finally, we note that fluctuations in total stress (thin line) are positively correlated with fluctuations in the mean vertical shear, with shear leading stress by a few days. Both time series are strongly autocorrelated, however, and the statistical significance of these correlations should be assessed with longer data. Although the correlation between total internal wave stress and vertical shear might be indicative of an important dynamical process, it is of little relevance to the problem of wave viscosity, since near-inertial motions do not contribute significantly to the effective internal wave stress (cf. relation (9)).

\section{INTERnal WaVE ENERgy Variability}

During IWEX, the energy in the internal wave field did not remain stationary. Figure 4 displays the evolution of the total energy density per unit volume,

$$
E=\frac{1}{2} \int_{f}^{N}\left(\left\langle u_{i}^{\prime} u_{i}^{\prime}\right\rangle+N^{2}\left\langle\zeta^{\prime 2}\right\rangle\right) d \omega
$$

estimated near the apex from the cross-spectral analysis at levels $1-5$ (between 604 and $639 \mathrm{~m}$ ). Two energy bursts, mainly due to large inertial oscillations, can be seen in mid-November and in early December. Similar features are found at $731 \mathrm{~m}$ and, to a certain extent, at $1023 \mathrm{~m}$ (Figure 6, middle panels). Time series of the total potential energy at $2050 \mathrm{~m}$ (not shown) suggests uncorrelated behavior at larger depths.

In the internal wave continuum, the energy behaves differently [Frankignoul, 1974]. A dominant feature of the observed continuum variability is a slow linear increase during the entire period of measurement, occurring throughout the whole thermocline. This increase is clearly seen in Figure 5, where the energy at the different levels has been scaled in a WKB manner $(E \sim N)$ to facilitate the comparison. By regression analysis we estimated the increase in internal wave continuum energy at $45 \%$ from the beginning to the end of the experiment. As discussed in the appendix, we believe the trend to be statistically significant. No statistically significant circular polarization was detected for the continuum.

Since the trimoor was extremely stable, the variability of internal wave energy is not induced by mooring motions. Furthermore, variations in the mean vertical temperature gradient are small (section 2), so that the variability cannot be caused by local variations in the Brunt-Väisälä frequency. The observed nonstationarity of the internal wave field is presumably due to variations in its energy sources and sinks.

In the following and in section 6, we compare the fluctuations in internal wave energy to changes in the larger-scale eddy field and the smaller-scale temperature fine structure field. A word of caution is needed at first: most energy time series discussed below are very short (covering perhaps onehalf eddy 'cycle'), non-Gaussian and generally autocorrelated. It was decided not to attempt the statistical testing of the observed correlations, and it should be emphasized that artificial correlations are expected from short realizations of processes with long, comparable length scales, even if they are statistically independent.

If the mean flow acts as a source of internal waves, one expects that the square mean vertical shear (referred to hereafter as (shear $)^{2}$ ) varies in the same manner as the total internal wave energy. The correlation will be strong if the interaction is quasi-local in space and time, but more difficult to observe if the waves propagate rapidly away. In Figure 6, time series of the $(\text { shear })^{2}$ estimated at 731 and $1023 \mathrm{~m}$ are compared with time series of the total internal wave energy (dominated by near inertial motions). Although the mid-November peak in $E$ at $731 \mathrm{~m}$ follows closely a peak in (shear) ${ }^{2}$, the correlation between the two curves is poor at this level. This occurs in part because the early December peak in $E$ has no counterpart in $(\text { shear })^{2}$. However. the comparison between the mean current at $731 \mathrm{~m}$ and higher levels suggests that strong vertical shears

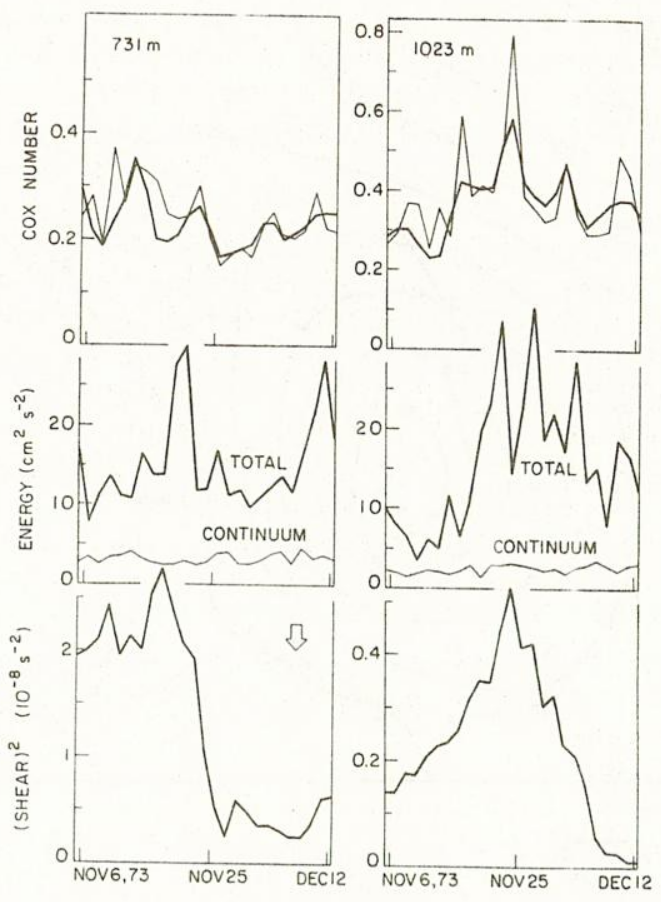

Fig. 6. Time behavior of the square mean vertical shear (lower panels), of the total energy in the total and continuum bands (middle panels), and of the Cox number (thick line in upper panels) and normalized Cox number (thin line in upper panels) at $731 \mathrm{~m}$ (left) and $1023 \mathrm{~m}$ (right). The arrow indicates the period of observed large vertical shear in the top of the thermocline (see text). 
(indicated by the arrow) may have occurred at the top of the thermocline a few days earlier, corresponding to high inertial wave activity near the apex (Figure 4). It could not be decided if this local shear event was due to instrument uncertainties (section 2). At $1023 \mathrm{~m}$, where the shear is best estimated, the total internal energy and the (shear) ${ }^{2}$ behave similarly, and their cross correlation function peaks to 0.65 when the (shear) ${ }^{2}$ leads by $75 \mathrm{hr}$. On the other hand, the energy in the internal wave continuum scems uncorrelated with (shear) ${ }^{2}$ at both levels.

Clearly, the IWEX data are too short to be conclusive, but the correlation between $E$ and (shear) $)^{2}$ observed at $1023 \mathrm{~m}$ is consistent with similar observations reported for the more extensive Mode and Polymode data [Frankignoul, 1976; Ruddick and Joyce, 1978].

\section{Temperature Finestructure Variability}

Joyce and Desaubies [1977] have shown that the variability in temperature difference, measured over vertical separations small compared to the vertical coherence scale of internal waves, could be interpreted as a measure of finestructure intensity. To the extent that this is related to thermal dissipation, the temperature difference variability monitors the intensity of vertical mixing.

The description of the temporal variability of the fine structure intensity during IWEX will be complemented by a discussion of some data taken during MODE, that show comparable spatial variations.

Temporal variability during IWEX. A Cox number $\left(\Delta T^{\prime 2}\right\rangle /$ $\langle\Delta T\rangle^{2}$ has been estimated in each 75-hour piece at $622 \mathrm{~m}$ (levels 1-5, Figure 4), $731 \mathrm{~m}$, and $1023 \mathrm{~m}$ (Figure 6). Since this estimate is dependent upon the level of internal wave vertical advection, we have also derived a normalized Cox number which takes into account some of the direct dependence of this estimator upon root mean square vertical displacement of isotherms by internal waves [cf. Joyce and Desaubies, 1977]. The two estimates are usually similar (cf. Figures 4 and 6) and we have chosen the uncorrected Cox number for further analysis. At $622 \mathrm{~m}$, the Cox number seems to fluctuate in time like the total internal wave energy $E$, but leads by a few days. At $731 \mathrm{~m}$, the Cox number is uncorrelated with $E$, but resembles (shear) $)^{2}$ (in particular, the normalized Cox number), although the correlations are small. At $1023 \mathrm{~m}$, the time behavior of the Cox number is very similar to one of (shear) $)^{2}$ and $E$. The correlation with (shear) $)^{2}$ is maximum at zero lag $(0.60)$, whereas the correlation with $E(0.55$ at zero lag) peaks when the Cox number leads $E$ by 75 hours (0.76). Correlations with the internal wave continuum are small.

As in section 5, the IWEX data are too short to decide whether the finestructure intensity varies like the mean square vertical shear and (or) the total internal wave energy, or if the correspondences apparent in Figures 4 and 6 are accidental. It should be pointed out that the variations in Cox number are somewhat smaller than the variations in total internal wave energy and (shear $)^{2}$. This may be due to a higher noise level in the finestructure data, or to the existence of different sources for temperature finestructure activity and its slow decay.

Spatial variability during Mode. Large-scale patterns in temperature finestructure activity have been sought in a 12-day period (May 14-26, 1973) during Mode where a broad spatial coverage of $30 \mathrm{WHOI} /$ Brown CTD stations were available. We chose a 200 decibar segment of the main thermocline beginning at the pressure of the $14.4^{\circ} \mathrm{C}$ isotherm. As an index we use a Cox number based on the temperature gradient
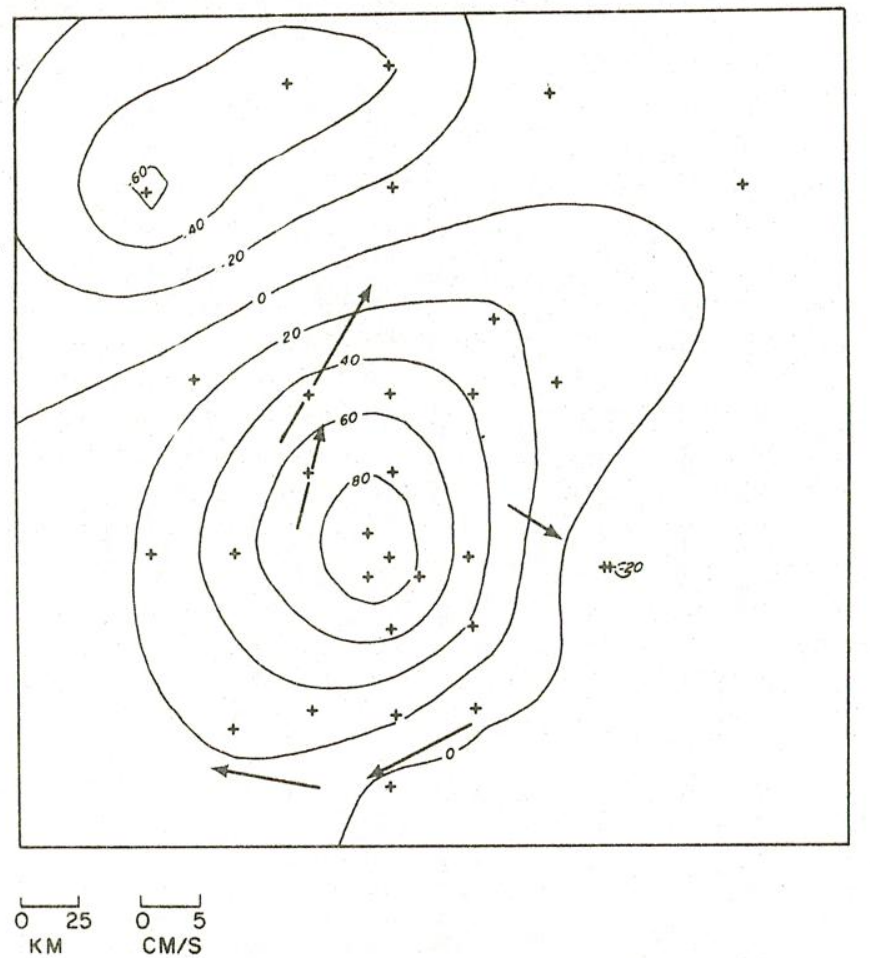

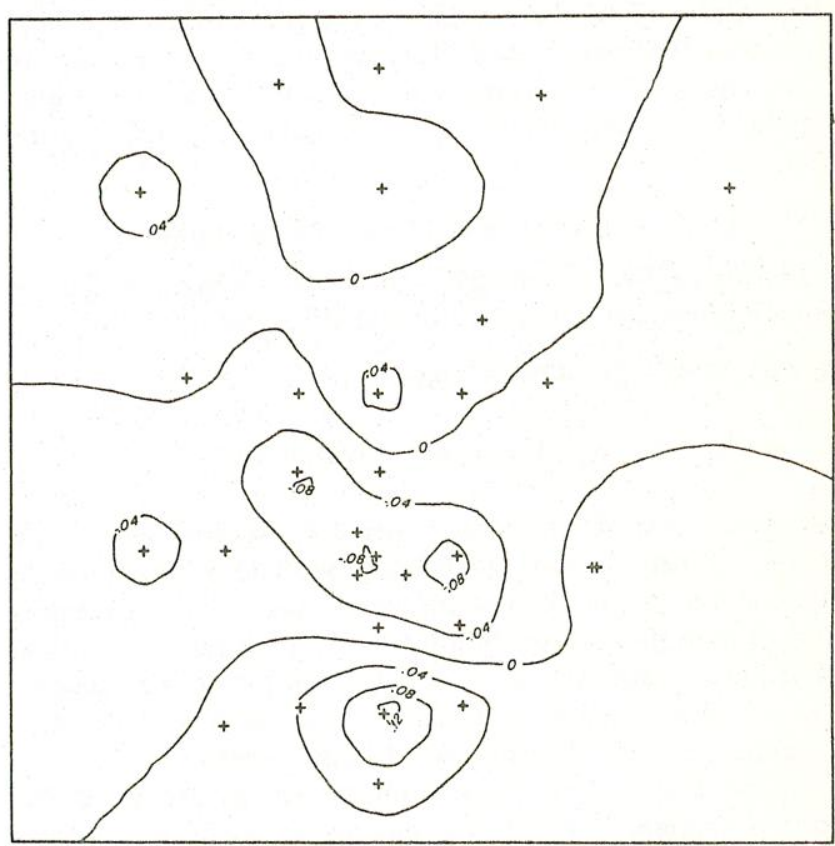

$\mathrm{O}_{K M}^{25}$

Fig. 7. (Left) Objective map of the $14.4^{\circ} \mathrm{C}$ isotherm displacement (in decibars, positive downward) from its mean level of $635 \mathrm{db}$ in the period May 14-26, 1973, during Mode. The vectors represent the averaged velocity at about $700 \mathrm{~m}$. (Right) Objective map of deviation of the Cox number about its mean of 0.38 during the same period. Crosses indicate position of CTD stations. 
variance between 2 and $10 \mathrm{~m}$, normalized by the square of the mean gradient over the 200 decibar segment. Joyce [1976] found this index to vary by a factor of 2 over a broad region of the N.W. Atlantic. The variations in the Mode data are less by a factor of 2 than in Joyce [1976]. Isotherm depth and Cox number have been hand contoured and also objectively mapped [Bretherton et al., 1976] in a box $300 \mathrm{~km}$ on a side centered on $28.5^{\circ} \mathrm{N}, 69.5^{\circ} \mathrm{W}$, with correlation lengths of 100 and $50 \mathrm{~km}$, respectively (Figure 7). The shorter scale for ('ox number variability was required for agreement between subjective and objective maps, thereby suggesting that the scales of thermocline displacement and finestructure variability are different. Figure 7 (left) shows that the Mode mesoscale eddy was nearly in the center of the box during this period, with regions of large isotherm slope to the northwest and southeast. Vectors represent the average velocity at a depth of about $700 \mathrm{~m}$, estimated from moored current meters [from Frankignoul, 1976]. Cox numbers are consistently lower than average within the eddy and larger to the south, just downstream of the maximum geostrophic shear. These data demonstrate that the finestructure activity is organized in mappable, large-scale patterns and is related to mesoscale motions, as seemed to be the case for the time variability of the finestructure during IWEX.

\section{Conclusions}

The IWEX experiment has provided the most complete and accurate data set to date to investigate the kinematics of deepsea internal waves. These data are rather short (42 days) for studying dynamics; and information on near-surface fields and large-scale flows are lacking as well. The present study aimed nonetheless at describing the variability of the internal wave field during IWEX, and at exploring the relation between this variability and the larger and smaller scale fields of motion. Particular emphasis was given to testing the prediction by Müller [1976] that internal waves contribute strongly to the vertical diffusion of large-scale flow momentum.

Although the IWEX data are particularly well suited for estimating the vertical flux of horizontal momentum from temperature and current measurements, the internal wave stress estimates are rather noisy and contaminated by a number of sources, many of which arise through the use of temperature data to estimate the vertical velocity. It was found that the vertical viscosity due to internal waves cannot be as large as proposed by Müller $\left(0.4 \mathrm{~m}^{2} \mathrm{~s}^{-1}\right)$, but that the data are too noisy to detect a possible wave-induced viscosity in absolute value of the order of $10^{-2} \mathrm{~m}^{2} \mathrm{~s}^{-1}$. Similar conclusions were reached by Ruddick and Joyce [1978] for the longer (but more noisy) Polymode data, hence there is little hope that the dynamical role of internal waves can be established in this manner. Since a vertical viscosity of $10^{-2} \mathrm{~m}^{2} \mathrm{~s}^{-1}$ would still be 1 or 2 orders of magnitude larger than commonly used in numerical modeling, the question remains of interest. Perhaps a more conclusive analysis will become possible with the development of current meters measuring directly the three components of the velocity.

The internal wave energy variability observed during IWEX suggests that some kind of dynamical coupling exists between internal waves and quasi-geostrophic eddies. The observed correlations in the time behavior of total internal wave energy and square mean vertical shear are of questionable statistical significance, but are similar to weak correlations reported in Mode [Frankignoul, 1976] and Polymode [Ruddick and Joyce, 1978] data. These correlations are consistent with the hypothesis of a quasi-local interaction between internal waves and larger-scale shear flows. An effective positive vertical viscosity of the order of $10^{-2} \mathrm{~m}^{2} \mathrm{~s}^{-1}$ is consistent with the magnitude of the energy fluctuations in all three data sets (using the method of Frankignoul [1976] and a relaxation time of 10 days for the internal wave field), but we feel that the observed correlations during IWEX are too uncertain to undertake such analysis here.

Finally, we found that the level of finestructure activity varies both in time (in the IWEX data) and in space (in Mode data). These fluctuations seem related to the variability of the quasi-geostrophic flow field, though could be possibly due to internal wave variability via wave breaking. Note, however, that Hogg et al. [1978] suggested from more extensive measurements around Bermuda that the finestructure activity (greatly enhanced near the island) was related to the geostrophic eddy flow but not to the internal wave field. More data should be investigated. The present study suggests that the temporal and spatial variability of internal waves and finestructure should be investigated in parallel with the variability of the eddy field.

\section{APPENDIX: Nonstationarity IN THE INTERNAL Wave Continuum}

As a simple model, we assume that the spectrum of the internal wave continuum grows linearly with time while preserving its shape, at a rate $\alpha$ which can be conveniently estimated by regression analysis. We use as dependent variable the logarithm $e(i, t)$ of the total energy density at the 25 frequencies (slightly less at the deepest level) dividing the internal wave continuum (see Müller et al. [1978] for details) and at depths from Table 1 ranging from 609 to $1023 \mathrm{~m}$. The index identifies each of the nine instruments and each of 25 different frequency bands. Setting

$$
e(i, t)=\langle e(i)\rangle+\hat{\alpha}(t-\langle t\rangle)+z(i, t) \quad t=1,25
$$

where the angle brackets indicate time averaging, the estimated slope $\hat{\alpha}$ is determined by minimizing

$$
\sum_{i} \sum_{t} z^{2}(i, t)
$$

For small energy increases as observed in the IWEX data, it can be easily shown that $\hat{\alpha}$ is a good estimator of $\alpha$. An increase in energy of $45 \%$ is found between the beginning and the end of the experiment. If we make the usual assumption that the errors $z(i, t)$ are uncorrelated random variables with constant variance, the confidence interval amounts to $\pm 4 \%$ in the increase. It was verified that the residuals are indeed uncorrelated in time. However, the residuals of the energy time series for different frequencies and (or) instruments are correlated to a certain degree. Thus the confidence interval is larger. Yet, there is little doubt that this is a true non-stationarity, since the slope is significantly non-zero at the $95 \%$ level if more than two of the energy time series are uncorrelated. It was also found that the slope was not significantly different when considering subsets of frequency or depth ranges, or using horizontal kinetic energy or potential energy rather than total energy.

In an earlier stage of this study, we had high-passed one record of velocity and temperature (A4 in Table 1) and constructed time series of the energy into two frequency bands (0.4-0.8 and $0.8-1.6 \mathrm{cph})$ using overlapping pieces of $9.4 \mathrm{hr}$ (203 pieces). The long term variability of the variance was investigated by comparing the sample cumulative distribution 
functions constructed from the first and second halves of the data, using a Kolmogorov-Smirnov two sample test. This nonparametric test was applied separately to the horizontal kinetic energy and the temperature variance in each band. In all four cases, the hypothesis of stationarity was rejected at the $95 \%$ confidence level. Thus, this case study was consistent with our conclusion of non-stationarity.

Acknowledgments. The authors wish to acknowledge the buoy group at the Woods Hole Oceanographic Institution who played a major role in obtaining the IWEX data. Nancy Pennington and Marlene Noble were of great help for some of the data analysis. We have much benefitted from discussions with the other IWEXers, in particular, M. Briscoe, N. Fofonoff, K. Hasselmann, P. Müller, D. Olbers, and J. Willebrand. This research was supported primarily by the Office of Naval Research under contract N00014-74-C-0262, NR083(0)4, and the Applied Physics Laboratory of the Johns Hopkins University, contract 372111 . Later support was provided to C. F. by the Deutsche Forschungsgemeinschaft (Sonderforschungsbereich 94), the Max-Planck Gesellschaft and the National Science Foundation, Office of the IDOE, under grant OCE 74-19782, and to T. J. by the Office of Naval Research under contract N00014-76-C-0197 NR083-400. Contribution 4124 of the Woods Hole Oceanographic Institution.

\section{REFERENCES}

Bretherton, F. P., The propagation of groups of internal gravity waves in a shear flow, Quart. J. Roy. Meterol. Soc., 92, 466-480, 1966.

Bretherton, F. P., R. Davis, and C. Fandry, A technique for objective analysis and design of oceanographic experiments applied to MODE-73, Deep Sea Res., 23, 559-582, 1976.

Briscoe, M. G., Preliminary results from the trimoored internal wave experiment (IWEX), J. Geophys. Res., 80, 3872-3884, 1975.

Briscoe, M. G., Gaussianity of internal waves, J. Geophys. Res., 82, 2117-2126, 1977.

Bryden, H. L., Horizontal advection of temperature for low-frequency motions, Deep Sea Res., 23, 1165-1174, 1976.

Desaubies, Y. J. F., A linear theory of internal wave spectra and coherences near the Vaisala frequency, J. Geophys. Res., 80, 895$899,1975$.

Frankignoul, C., Preliminary observations of internal wave energy flux in frequency, depth-space, Deep Sea Res., 21, 895-909, 1974.

Frankignoul, C., Observed interaction between oceanic internal waves and mesoscale eddies, Deep Sea Res., 23, 805-820, 1976.

Garrett, C. J. R., and W. H. Munk, Space-time scales of internal waves: A progress report, J. Geophys. Res., 80, 291-297, 1975.
Hogg, N. G., E. J. Katz, and T. B. Sanford, Eddies, islands, and mixing, J. Geophys. Res., 83, 2921-2938, 1978.

Jenkins, (. M., and D. G. Watts, Spectral Analysis and Its Applications, 5.5 pp., Holden-Day, San Francisco, Calif., 1969.

Joyce, T. M., Large scale variations in small scale temperature/salinity fine stricture in the main thermocline of the northwest Atlintic, Deep Sia Res., 23, 1175-1186, 1976.

Joyce, T. M., and Y. Desaubies, Discrimination between internal waves and temperature finestructure, J. Phys. Oceanogr., 7, 2:-32, 1977.

Leaman, K. D., Observations on the vertical polarization and energy flux of near-inertial waves, J. Phys. Oceanogr., 6, 894-908, 1976.

McComas, C. M., Equilibrium mechanisms within the oceanic internal wave field, J. Phys. Oceanogr., 7. 836-845, 1977.

McComas, C. M., and F. P. Bretherton, Resonant interactions of oceanic internal waves, J. Geophys. Res., 82, 1397-1412, 1977.

Müller, P. M., On the diffusion of momentum and mass by internal gravity waves, J. Fluid Mech., 77, 789-823, 1976.

Müller, P. M., and D. J. Olbers, On the dynamics of internal waves in the deep ocean, J. Geophys. Res., 80, 3838-3860, 1975.

Müller, P. M., D. J. Olbers, and J. Willebrand, The IWEX spectrum, J. Geophys. Res., 83, 479-500, 1978.

Nuttal, A. H., Spectral estimation by means of overlapped fast Fourier transform processing of windowed data, NUSC Rep. 4169. Nav. Underwater Syst. Center, New London, Conn., 1971.

Olbers, D. J., Non-linear energy transfer and the energy balance of the internal wave field in the deep ocean, J. Fluid Mech., 74, 375-389, 1976.

Perrson, J., Variability and covariability of modified spectral estimates, IEEE Trans. Acoust. Speech Signal Process, 22, 158-160, 1974.

Ruddick, B. R., Observations of interaction between the internal wave field and low frequency flows in the North Atlantic, Tech. Rep. 77. 68, Woods Hole Oceanogr. Inst., Woods Hole, Mass., 1977.

Ruddick, B. R., and T. M. Joyce, Observations of interactions between the internal wavefield and low frequency flows in the North Atlantic, J. Phys. Oceanogr., in press, 1978.

Sanford, T. B., Observations of the vertical structure of internal waves, J. Geophys. Res., 80, 3861-3881, 1975.

Tarbell, S., M. G. Briscoe, and D. Chausse, A compilation of moored current data and associated oceanographic observations, 1973 Internal Wave Experiment (IWEX), Tech. Rep. 75-68, vol. IX, Woods Hole Oceanogr. Inst., Woods Hole, Mass., 1976.

(Received May 25, 1978; revised July 26, 1978; accepted July 31, 1978.) 


\begin{tabular}{|c|c|}
\hline REPORT DOCUMENTATION PAGE & $\begin{array}{c}\text { READ INSTRUCTIONS } \\
\text { BEFORE COMPLETING FORM }\end{array}$ \\
\hline \begin{tabular}{l|l|} 
1. REPORT NUMBER & 2. GOVT ACCESSION NO. \\
WHOI $-81-17$ & \\
\end{tabular} & 3. RECIPIENT'S CATALOG NUMBER \\
\hline \multirow[t]{2}{*}{$\begin{array}{l}\text { 4. TITLE (and Subulia) } \\
\text { ON THE INTERNAL WAVE VARIABILITY DURING THE } \\
\text { INTERNAL WAVE EXPERIMENT (IWEX) }\end{array}$} & $\begin{array}{l}\text { 5. TYPE OF REPORT A PERIOU COVERED } \\
\text { Technical }\end{array}$ \\
\hline & $\begin{array}{l}\text { 6. PERFORMING ORG. REPORT NUMBER } \\
\text { WHOI CONt. \#4124 }\end{array}$ \\
\hline $\begin{array}{l}\text { 7. AUTHOR(a) } \\
\text { Claude Frankignoul and Terrence M. Joyce }\end{array}$ & $\begin{array}{l}\text { 8. CONTRACT OR GRANT NUMBER(a) } \\
\text { NO0014-74-C-0262; * } \\
\text { N00014-76-C-0192; } \\
\text { OCE 74-19782 }\end{array}$ \\
\hline $\begin{array}{l}\text { 9. PERFORMING ORGANIZATION NAME AND ADDRESS } \\
\text { Woods Hole Oceanographic Institution } \\
\text { Woods Hole, Massachusetts } 02543\end{array}$ & $\begin{array}{l}\text { 10. PROGRAM ELEMENT. PROJECT, TASK } \\
\text { AREA \& WORK UNIT NUMBERS } \\
\text { * NR } 083-004 \\
\text { NR } 083-400\end{array}$ \\
\hline \multirow{2}{*}{$\begin{array}{l}\text { 11. CONTROLLING OFFICE NAME AND ADDRESS } \\
\text { NORDA/National Space Technology Laboratory } \\
\text { Bay St. Louis, MS } 39529\end{array}$} & $\begin{array}{l}\text { 12. REPORT DATE } \\
\text { Apri } 1981\end{array}$ \\
\hline & 13. NUMBER OF PAGES \\
\hline \multirow[t]{2}{*}{ 14. MONITORING AGENCY NAME \& ADDRESS(if different from Controlline Offico) } & $\begin{array}{l}\text { 15. SECURITY CLASS. (of this roport) } \\
\text { Unclassified }\end{array}$ \\
\hline & $\begin{array}{l}\text { 15a. DECLASSIFICATION/DOWNGRADING } \\
\text { SCHEDULE }\end{array}$ \\
\hline
\end{tabular}

Approved for public release; distribution unlimited.

17. DISTRIBUTION STATEMENT (of the abstract ontered in Block 20, if difforent from Roport)

18. SUPFLEMENTARY NOTES

Feprinted from: Journal of Geophysical Research 84 (C2): 769-776. (February 1979).

19. KEY WORDS (Continue on roverse oide if noceseary and tdentify by block number)

1. Internal wave variability

2. Internal Wave Experiment (IWEX)

3. Momentum exchange between waves and currents

20. ABSTRACT (Continue on reveree elde if necoesary and identify by block number)

See reverse 
The relation between internal wave variability and larger and smaller scales of motion is investigated, using the IWEX data set. To investigate the role of internal waves in the vertical diffusion of large scale momentum, the time variability of the vertical flux of horizontal internal wave momentum (estimated from the temperature and current data) is compared to that of the mean vertical shear. It is found that internal waves cannot cause a vertical viscosity as large as proposed by Muller (1976), but that the data are too noisy to detect a possible wave-induced viscosity in absolute value of the order of $10-2 \mathrm{~m}^{2} \mathrm{~s}-1$ or less. Similarities in the time behavior of the total internal wave energy and that of the square mean vertical shear suggest that some kind of dynamical coupling exists between internal waves and larger scale flows. There is some evidence that the level of temperature finestructure activity also varies in a related way. An analysis of CTD station data taken during Mode demonstrates the mappabi1ity of the finestructure activity, and again suggests a relation with the geostrophic eddy flow. 


\section{MANDATORY DISTRIBUTION LIST}

FOR UNCLASSIFIED TECHNICAL REPORTS, REPRINTS, AND FINAL REPORTS PUBLISHED BY OCEANOGRAPHIC CONTRACTORS

OF THE OCEAN SCIENCE AND TECHNOLOGY DIVISION

OF THE OFFICE OF NAVAL RESEARCH

(REVISED NOVEMBER 1978)

1 Deputy Under Secretary of Defense (Research and Advanced Technology)

Military Assistant for Environmental Science Room 3D129

Washington, D.C. 20301

Office of Naval Research

800 North Quincy Street

Arlington, VA 22217

ATTN: Code 483

ATTN: Code 460

ATTN: $102 B$

I CDR J. C. Harlett, (USN)

ONR Representative

Woods Hole Oceanographic Inst.

Woods Hole, MA 02543

Commanding Officer

Naval Research Laboratory

Washington, D.C. 20375

6 ATTN: Library, Code 2627
12 Defense Documentation Center Cameron Station

Alexandria, VA 22314

ATTN: DCA

Commander

Naval Oceanographic Office NSTL Station

Bay St. Louis, MS 39522

ATTN: Code 8100

ATTN: Code 6000

ATTN: Code 3300

$1 \quad$ NODC/NOAA

Code D781

Wiscons in Avenue, N.W.

Washington, D.C. 20235 


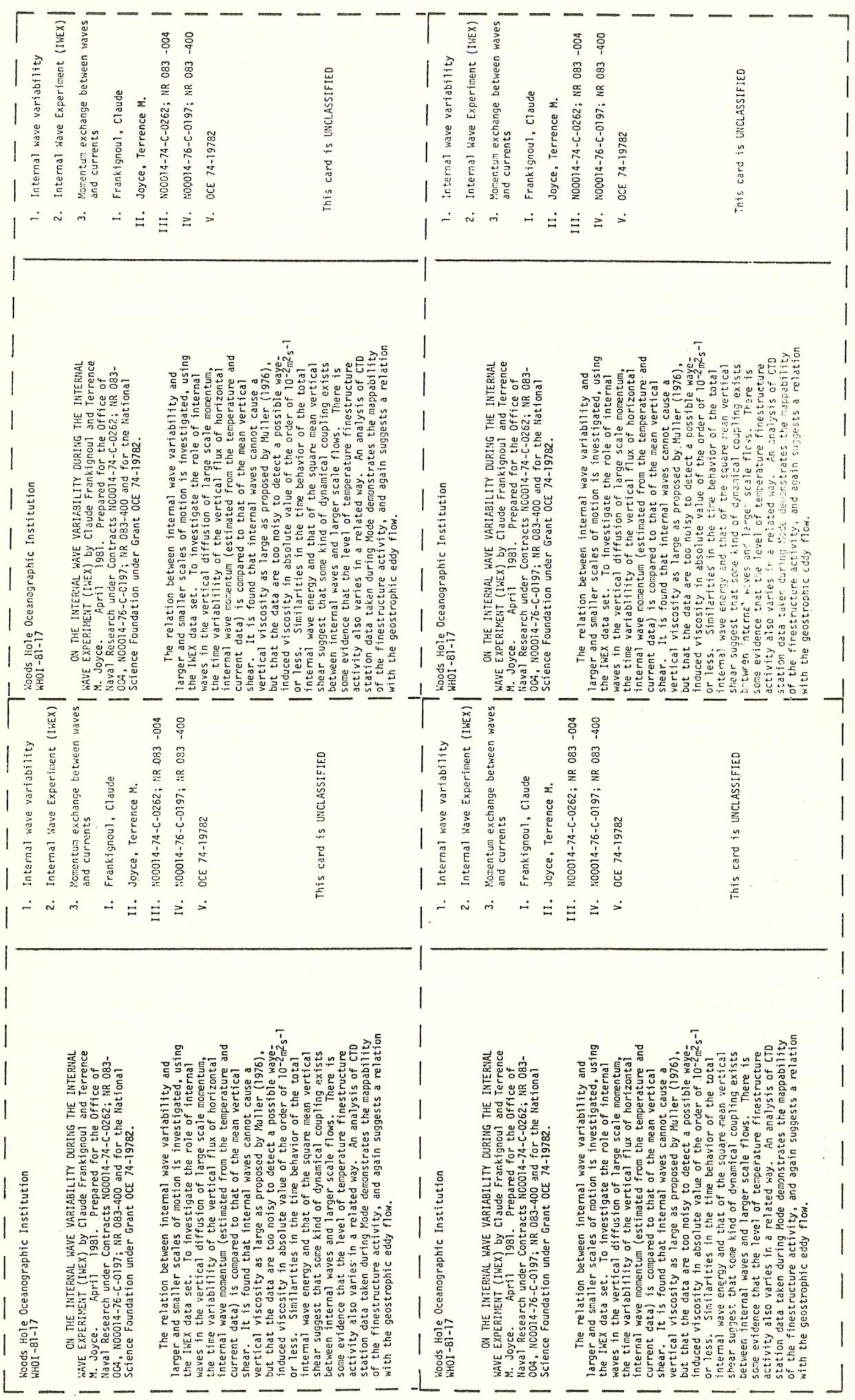

